\title{
Negócio prototipando: percepções de designers e gestores sobre a prototipagem de modelos de negócios
}

Prototyping business: perceptions of designers and managers on the prototyping of business models

MEYER, Guilherme; Doutor; Unisinos

gcmeyer@unisinos.br

MAKARIEWICZ, Isadora; Mestre; Unisinos

isadoralongo@gmail.com

\section{Resumo}

O cenário atual vem exigindo das organizações novas interpretações e olhares para a construção dos modelos de negócios. O design tem condições de colaborar com esse processo. Muito pelo seu modo de agir, que está relacionado com maior propensão a correr riscos, assim como por seu olhar multidisciplinar, tanto para os problemas quanto para os projetos. Em relação ao modo como os designers agem, a pesquisa irá colocar uma lente na perspectiva do protótipo, como elemento capaz de revelar novos saberes sobre uma temática Portanto, o objetivo desta pesquisa foi explorar o papel da prototipagem na modelagem de negócios. Para tanto, foi desenvolvido um workshop, com o desafio de que os participantes construíssem um modelo de negócios a partir dos materiais disponibilizados. Ainda foram realizados dois grupos focais. Os resultados alcançados sugerem que, apesar dos profissionais enxergarem distintas vantagens, ambos vislumbram a atividade produtiva na construção de modelos de negócios.

Palavras Chave: Modelagem de Negócios; Prototipagem; Processo de Design.

\section{Abstract}

The current scenario has been demanding from organizations new interpretations and looks for the construction of business models. The design is able to collaborate with this process. Much by his way of acting, which is related to a greater propensity to take risks, as well as his multidisciplinary approach, both for problems and for projects. Regarding the way designers act, the research will put a lens in the perspective of the prototype, as an element capable of revealing new knowledge about a thematic. Therefore, the objective of this research was to explore the role of prototyping in business modeling. For that, a workshop was developed, with the challenge that the participants build a business model from the available materials. Two focal groups were also held. The results obtained suggest that, although the professionals see different advantages, both look at the productive activity in the construction of business models.

Keywords: Business Model; Making; Design Process. 


\section{Introdução}

O século XXI tem mostrado um crescimento desenfreado de tecnologia e de soluções que jamais foram vivenciadas. Novas necessidades e novas tendências surgem a todos os instantes, alterando mais rapidamente os contextos empresariais e tornando os planos de projetos tradicionais incapazes de acompanhar essas transformações. (REUTHER; JETTON, 2013).

Esses novos desafios que se voltam para novas expressões organizacionais são expressos de alguma forma pelo modelo de negócio. Para Teece (2009), é a forma como a empresa irá compreender as necessidades dos clientes a fim de criar um produto ou serviço condizente com sua disposição monetária de adquiri-lo; esse processo é, comumente, chamado de criação de valor, pois diz respeito à forma como a empresa se organiza para criar seus produtos, vender e obter ganhos financeiros ao final desse processo. Chesbrough (2002) corrobora com a discussão ao afirmar que o modelo de negócio é um dispositivo que busca encontrar o foco entre o desenvolvimento da tecnologia e a criação de valor econômico. Teece (2009) ainda argumenta que uma análise histórica mostra a necessidade das empresas em oferecer produtos e serviços com propostas de valor convincentes para os consumidores. Nesse sentido, o processo de concepção e de implementação dos produtos, por meio dos procedimentos de gestão, tornam-se importantes, mas precisam ser repensados.

O design a partir de seu modo de pensar pode ser o um aliado das organizações para enfrentar essas rápidas transformações. Cross (2011) acredita que os designers têm uma maior propensão a correr riscos, assim como, têm um olhar multidisciplinar, tanto para os problemas, quanto para os projetos. $\mathrm{E}$, portanto, têm maior familiaridade com a complexidade da sociedade atual, que vem exigindo outras formas de lidar com os problemas. Tal perspectiva é importante, uma vez que se perceba a insuficiência do modelo linear de problema-solução. O raciocínio abdutivo é, também, bastante presente na maneira como os designers lidam com suas atividades, uma vez que, através da abdução o designer busca fornecer significado a fim de que possa transferir conhecimento entre o verdadeiro propósito ou função de alguma atividade e uma forma apropriada de objeto que satisfaça o propósito.

A partir desse enfoque, sobre o modo como os designers agem, o artigo, que é oriundo de uma pesquisa mais ampla cujo estudo abordou diferentes aspectos do protótipo, irá colocar uma lente na perspectiva do protótipo, como elemento capaz de revelar novos saberes sobre uma temática, uma vez que o protótipo tem um papel significativo, mais plural e rico do que o papel tradicional de testagem daquilo que está sendo projetado. Seu objetivo está pautado em uma perspectiva que visa estimular reflexões como um artifício de abertura, discussões e descobertas no espaço de projeto.(LIM et al. 2008). É necessário que o protótipo atinja uma dimensão física e com volume para que os participantes sejam capazes de envolver-se em outras dinâmicas e consigam vislumbrar novas perspectivas do que está sendo projetado. Nesse sentido o protótipo não tem a pretensão de ser o produto da série, mas ser um tipo de operação que o design realiza para que o processo progrida de forma mais rica. Essa potencialidade dos protótipos também é discutida por Galey e Ruecker (2010) quando afirmam que esses artefatos tem objetivos distintos de sua forma e função convencional e podem alcançar uma nova perspectiva de serem fonte de conhecimento.

A construção do protótipo está vinculada à própria atividade de materialização, a prototipagem, e auxilia os designers no refinamento de suas ideias. Esse processo iterativo 
projetual permite que os participantes possam envolver-se em uma dinâmica diferenciada que não tem como consequências respostas automáticas, mas, sim, momentos criativos que surgem a partir do manuseio e das discussões provenientes do próprio ato de construção projetual. (DOW et.al., 2009).

Outrossim, a pesquisa justifica-se uma vez que a forma como a gestão tem lidado com os modelos de negócios possui alguns limites, e as rápidas transformações exigem novas formas de lidar com toda diversidade presente no ambiente tanto interno quanto externo. (TEECE, 2009). Nesse contexto, o design tem potencial para buscar novas perspectivas e revelar novos aspectos sobre os modelos de negócios. O design é generativo e lida com a ideia de materialização que facilita as conversas; a atividade de prototipagem funciona como um palco de discussão e conversa, revelando aspectos novos sobre o que está sendo discutido. (DUNN, 2007; GURSOY E OZKAR, 2015).

Em meio a essas discussões sobre modelos de negócios ${ }^{1}$, modo de agir dos designers, protótipo e prototipagem, o objetivo do trabalho é explorar o papel da prototipagem na modelagem de negócios na percepção de designers e gestores. Dessa forma, a fim de viabilizar o estudo, foi desenvolvido um workshop com especialistas da gestão e do design, utilizando-se do expediente da prototipagem com ponto central, uma vez que o design se distingue pelo modo como ele opera.

\footnotetext{
${ }^{1}$ Modelos de negócios: prototipar negócios, uma possível confusão deve ser evitada, para o
} 


\section{Modelos de Negócios}

A partir do século XXI, com a ascensão das empresas ponto.com alavancada pelo desenvolvimento desenfreado de tecnologias, o acesso democratizado à informação, bem como a aproximação das fronteiras econômicas mundiais, alterou, de forma significativa, a maneira como as organizações têm desenvolvido seus negócios. Esse processo tem demandado das empresas novos alinhamentos estratégicos, assim como formatos que possam atender a rapidez informacional vivenciada hoje. Essa reconfiguração perpassa desde seu olhar estratégico até mesmo ajustes internos para que as empresas possam enfrentar consumidores cada vez mais bem informados e críticos em suas escolhas, visto que esses têm em mãos um acesso bastante facilitado das diversas possibilidades, devido à internet, permitindo-Ihes um maior poder de decisão e escolha sobre aquilo que desejam adquirir e consumir. (MAURI, 1996; WOOD, 1999; TEECE, 2010).

Em vários setores da economia, já não é mais possível seguir a lógica da demanda que impulsiona o desenvolvimento de produtos e serviços, pois a quantidade de opções aos consumidores é cada vez maior e, portanto, faz-se necessário que as organizações se reinventem. Vários são os fatores que levam a essa era do conhecimento; o crescimento da internet e o consequente comércio eletrônico são alguns dos exemplos que contribuíram para acelerar esse processo. Sob essa perspectiva, o desenvolvimento de um modelo de negócios vem ao encontro dessa discussão, pois traduz o negócio em uma forma simplificada, visto que "descreve o design ou arquitetura dos mecanismos de criação, entrega e captura de valor que emprega" (TEECE, 2010, p. 172, tradução nossa), possibilitando uma visão do todo da organização, além de permitir rápidas mudanças na configuração dos negócios em si, devido, especialmente, ao seu formato simples de apresentação. Essa visão conceitual sobre modelos de negócios elucidada por Teece (2010) também é compartilhada por Chesbrough (2002) e Osterwalder (2012), que dizem que a essência de um modelo de negócios está na definição da forma pela qual a empresa agrega valor aos clientes, da forma como atrai os clientes para pagar algum valor monetário pelo produto ou serviço e, por fim, da forma como converte esses pagamentos em lucros. Nesse sentido, e em complemento à visão, Osterwalder, Pigneur e Tucci $(2005$, p.3) consideram que o modelo de negócios é

uma ferramenta conceitual que contém um conjunto de objetos, conceitos e suas relações com o objetivo de expressar a lógica de negócios de uma empresa específica. Portanto, devemos considerar que os conceitos e relações permitem uma descrição simplificada, tanto de representar o valor fornecido aos clientes, quanto às consequências financeiras. (tradução nossa).

Sob essa perspectiva, um framework bastante conhecido e utilizado no desenvolvimento de novos negócios é o business model canvas (BMC) desenvolvido por Osterwalder e Pigneur (2010), o modelo consiste no preenchimento de nove blocos que correspondem a uma primeira versão do modelo de negócios. Este auxilia na visualização macro do negócio. O livro, que contém o framework desenvolvido pelos autores, também aborda um início de introdução sobre design, a partir de uma abordagem que liga o design à construção de negócios. Essas discussões sobre modelos de negócios, bem como o surgimento de ferramentas como o business model canvas (BMC), segundo Gudiksen et al (2014), são um importante avanço para o campo. Em sua visão o BMC, especificamente, "oferece uma plataforma simples, visual com uma proposição de uma 
linguagem compartilhada" (p.16 tradução livre da autora). Por outro lado, segundo o autor, as abordagens atuais trabalham com uma visão mais documental e menos a partir de uma abordagem de aprendizado tangível e orientadas para o desenvolvimento manual. $\mathrm{O}$ design a partir de seus processos orientados para o desenvolvimento de protótipos, pode ser um importante aliado para construção de modelos de negócios.

\section{Modo de agir do designer}

De forma geral, os projetos de design buscam tratar de problemas sociais e a realidade dos usuários. Alguns autores argumentam que os designers lidam com problemas de formas distintas, buscando, de certa forma, uma perspectiva interdisciplinar. Os referidos problemas requerem metodologias específicas e que proponham melhores soluções (FRIEDMAN, 2003). No design, os problemas são tratados de uma forma particular e são considerados wicked problems, pois consideram aspectos socioculturais, econômicos, filosóficos, entre outros para a composição tanto de sua proposta inicial quanto das soluções finais e não podem ser considerados etapas lineares que seguem um caminho único do problema para solução. (BUCHANAN,1992).

A sociedade, cada vez mais complexa, vem exigindo outras formas de lidar com os problemas, sendo que a forma linear de solução vem se mostrando, a cada evento, mais ineficaz, levando em consideração a propensão a correr riscos, uma vez que, para tanto, é necessário um acompanhamento mais atento dessas transformações. Cross (2001) corrobora essa visão ao afirmar que a maneira pelo qual os designers raciocinam está relacionada com uma maior propensão a correr riscos, assim como com um olhar multidisciplinar, tanto para os problemas quanto para os projetos.

Michlewski (2008) considera que os designers são um recurso estratégico importante para as organizações, principalmente em momentos de mudanças, porém, mesmo que a relevância desses profissionais já tenha sido comprovada em estudos científicos, o autor identificou uma lacuna de estudos no ambiente prático. Nesse sentido, analisou empiricamente a natureza da atitude dos designers por meio de um estudo com grandes lideranças de escritórios bemsucedidos, sendo uma descrição bastante rara das práticas de design. Tal estudo possibilitou ao autor concluir que existem cinco atitudes principais relacionadas aos designers. São elas: consolidar os significados multissensoriais; Criar, trazer à vida; Operar com incertezas; Estética polissensorial e empatia.

\subsection{Protótipos e prototipagem}

A partir desse enfoque sobre o modo como os designers agem, o artigo coloca uma lente na perspectiva do protótipo como um elemento passível de manuseio e produtor de conhecimento. Protótipo e prototipagem são conceitos que acompanham o processo de design e, apesar de sua terminologia ser bastante similar, possuem significados distintos e que podem ser confundidos. Portanto, entende-se por protótipo como as "formas representativas e manifestadas de ideias de design" e por prototipagem como "a atividade de fazer e utilizar protótipos em design". (LIM et al., 2008, p.10, tradução nossa).

O termo protótipo, a partir de um primeiro olhar, pode ser visto como um objeto que auxilia em testes de conceitos ou como o primeiro da série. É comumente utilizado em projetos, tanto de engenharia quanto de design. No entanto, um olhar mais contemporâneo discute o 
protótipo a partir de uma perspectiva mais ampla que estimula reflexões como um artifício de abertura e de descobertas em um espaço de projeto (LIM et al., 2008). Essa abordagem leva em consideração que o protótipo tem como objetivo tornar-se volumétrico para que as pessoas possam se envolver em um outro tipo de percepção do que está sendo projetado. Torna-se uma atividade de experimentação, de materialização, que envolve testes, mas vai além desses; nesse sentido, não tem a pretensão de ser o produto da série, mas ser um tipo de operação que o design realiza para que o processo progrida de forma mais rica.

Galey e Ruecker (2010) corroboram esse novo olhar ao protótipo, afirmando a necessidade do designer em se tornar um questionador do processo, visto que, por muito tempo, seguiu-se apenas a forma e a função dos artefatos e que, em determinados contextos, artefatos e protótipos têm objetivos distintos a sua função convencional. Isso garantiu uma nova perspectiva para formas não convencionais: ser fonte de conhecimento. Os autores argumentam que cada protótipo apresenta uma teoria, o pode estar relacionado ao fato de sua construção estar ligada ao "pensar através do fazer" (p. 3). Ingold (2013) também colabora com a discussão ao afirmar que o desenvolvimento de conhecimento a partir da prototipagem tem se mostrado um importante aliado para o desenvolvimento de novos conhecimentos, principalmente no campo do design. Ainda, é capaz de envolver o raciocínio sobre as relações e conexões entre os materiais e formas a fim de considerar que as alterações dos projetos possam tornar-se propriedades de interesse. (HARRISON et al., 2005).

Segundo Dunn (2007) os protótipos são produções materiais que representam muito mais do que suas dimensões físicas, mesmo que, por vezes, possam conter níveis de abstração ou simplicidade que são essenciais para o processo de projeto, uma vez que são ferramentas que promovem o pensamento e a comunicação entre o design e o designer.

A prototipagem, por sua vez, como comentado anteriormente, envolve-se na própria atividade de criação e é o conjunto de atividades e processos que engloba o fazer em design. Segundo os autores Dow et al. (2009), a prototipagem auxilia os designers no refinamento das suas ideias. Trata-se de um processo interativo, o qual oscila entre a criação e feedbacks, uma vez que as descobertas, ao longo do caminho, fazem parte da construção e não são respostas automáticas consequentes do processo. De certa forma, a maneira como as pessoas envolvidas encaram os problemas apresentados trarão insights e potencializarão ou esconderão determinados problemas. Ainda, esses momentos de insights criativos conduzem os designers ao desenvolvimento de protótipos para que possam ser levantadas questões a partir de seu manuseio e observações por meio da interação e que acabam por gerar novas ideias. Gursoy e Ozkar (2015) corroboram essa visão ao afirmar que o design participa de um tipo de articulação que se volta para a produção de representações abstratas, formas ou modelos cujo objetivo posterior é a própria materialização do que foi projetado, participando de um processo complexo de interação e produção de conhecimento entre designers e artefatos.

A emergência na discussão de novas formas de desenvolver negócios a partir de novas perspectivas levou a empresa Lego a difundir sua metodologia interna de desenvolvimento de projetos em um novo negócio, a Lego Serius Play (LSP). A utilização desse conceito traz aos times de trabalho uma discussão diferenciada, uma vez que utiliza das próprias mãos no desenvolvimento de ideias e pensamentos, originando uma conexão "mãos-cérebro" (GRIENTIZ; SCHMIDT, 2012, p.27, tradução nossa), o que permite criar uma extensão física dos 
pensamentos. Reuther e Jetton (2013) corroboram a visão, afirmando que existe uma íntima ligação entre o pensamento do cérebro e as mãos humanas, já que construir algo brincando "desencadeia pensamentos e maneiras de ver coisas que muitos adultos não estão cientes" (p. 34, tradução nossa).

Essa discussão sobre novas formas de desenvolvimento de negócios também incentivou os autores Gudiksen et al. (2014) a pesquisarem como atividades colaborativas com materiais físicos poderiam engajar os participantes a fim de propor-lhes novas formas de discussão e aprendizado. $\mathrm{O}$ autor propôs diferentes atividades com diferentes estímulos e participantes para observar como que o processo de prototipagem poderia ser ou não eficaz em cada uma das situações. Estas trouxeram à tona uma nova proposta de como é possível discutir problemas e modelos de negócios por meio de atividades práticas, uma vez que estimulam a criatividade, o aprendizado e a interação entre diferentes agentes que compõem o ecossistema da organização. Para os autores, esse processo de colaboração no desenvolvimento de negócios traz benefícios às empresas. Os pontos de vista diferentes criam as configurações e atividades pelas ferramentas que conduzem a diálogos qualitativos, promovendo a formulação de problemas e cenários futuros do negócio, uma vez que têm potencial de criar novas perspectivas e repensar os modelos de negócios. Chesbrough (2010) corrobora com a visão de construção de modelos de negócios pela ótica de design ao afirmar que as organizações que convidam clientes, fornecedores e parceiros para o processo de inovação, bem como as empresas que se comprometem com a experimentação contínua, são mais avançadas, melhores na criação de plataformas adaptativas e preparadas para responder, de forma mais facilitada, a mudanças.

\section{Método e Resultados}

A partir desse contexto de pesquisa seu objetivo geral é explorar o papel da prototipagem na modelagem de negócios na percepção de designers e gestores. A fim de viabilizar o estudo, foi inicialmente desenvolvido um workshop de design. O workshop teve duração de dois períodos de 2 horas e 45 minutos de trabalho cada, sendo que o primeiro interessado na conceituação e prototipagem e o segundo interessado na apresentação do modelo de negócio e execução dos grupos focais. O critério para a escolha dos designers é ter formação na área e para os gestores, ter envolvimento com modelagem de negócios em âmbito gerencial. Foram convidados quatro designers e quatro gestores, totalizando dois grupos de trabalho, cada um integrando dois designers e dois gestores. Para o workshop o procedimento de trabalho adotado contou com a entrega de um briefing de projeto cujo objetivo era o desenvolvimento de um modelo de negócios para um gerente da indústria de alimentos que desejava abrir seu próprio negócio no ramo alimentício. Como subsídio informacional foram entregues cinco infográficos elaborados pelos autores com informações contextuais e não contextuais. Ainda cada equipe recebeu o mesmo "kit de prototipagem" com diversos materiais para serem utilizados tanto para discussões como para elaboração do protótipo final do modelo de negócios conforme a figura 1.

Figura 1 - Kit entregue para cada grupo 


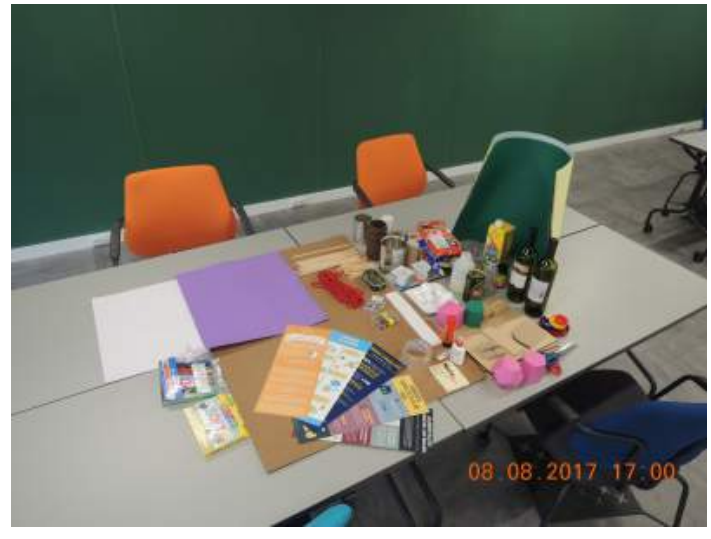

Fonte: Elaborada pelos autores

Por fim, antes de iniciar a atividade os participantes foram sensibilizados sobre o entendimento de protótipo e prototipagem, bem como de modelos de negócios. Ao final do processo ambos os grupos alcançaram os objetivos do da atividade e propuseram modelos de negócios com potencial de serem executados, conforme ilustram as figuras 2 e 3.

Figura 2 - Modelo de Negócios grupo 1.

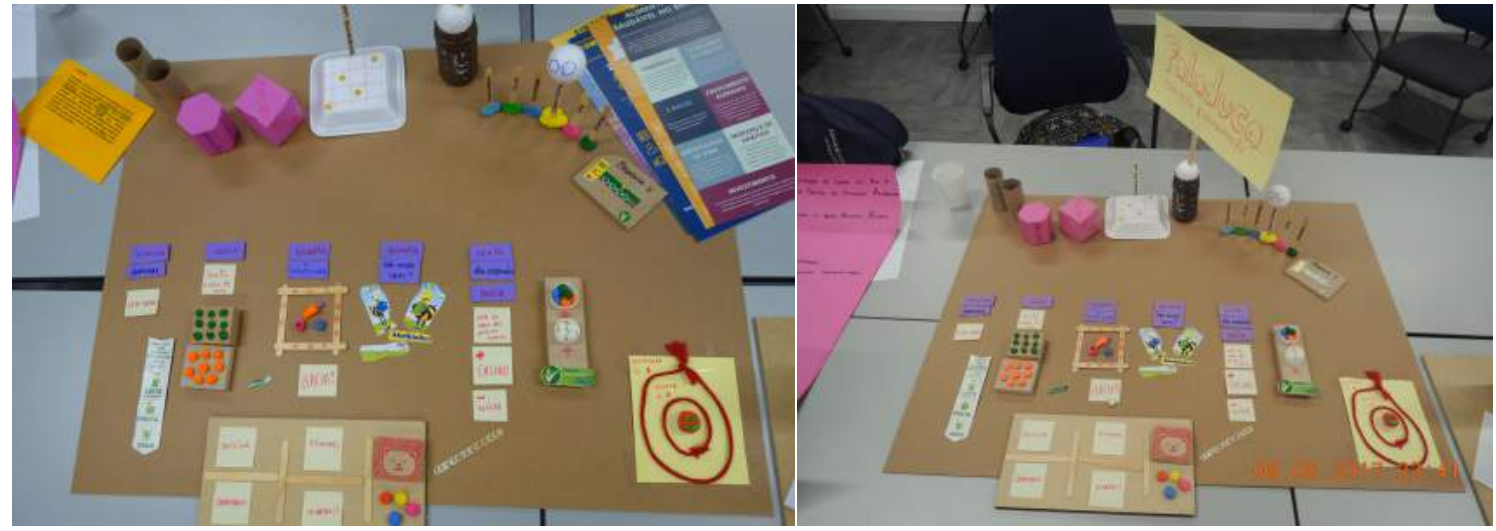

Fonte: Elaborada pelos autores

Figura 3 - Modelo de Negócios grupo 2

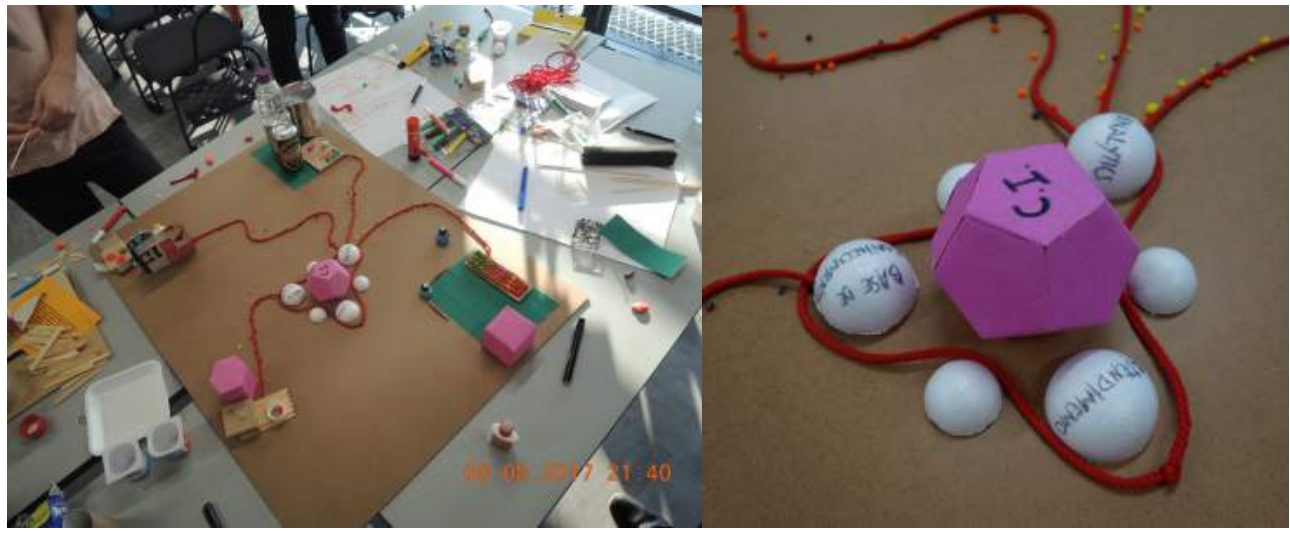

13 Congresso Brasileiro de Pesquisa e Desenvolvimento em Design, Univille, Joinville (SC) 
Fonte: Elaborada pelos autores

Após o workshop foi realizado dois grupos focais um com gestores e um com os designers de cada grupo. Os dados coletados foram analisados através da técnica de análise de conteúdo o que permitiu a identificação de quatro categorias para o grupo focal realizado com gestores e oito com o desenvolvido com os designers. A síntese das categorias encontradas em cada grupo focal pode ser apreciada em dois quadros a seguir. Optamos por não apresentar o quadro completo de análise, isto é, envolvendo as unidades de análise todas, por restrição de espaço. Algumas das unidades, contudo, são recuperadas sempre que necessário na seção de discussão.

Quadro 1 - Síntese das categorias do grupo focal com gestores.

\begin{tabular}{ll}
\hline Categoria & Definição \\
\hline 1. Gerar insights & $\begin{array}{l}\text { Os materiais têm potencial para uma capacidade criativa que gera } \\
\text { novas visões sobre o que pode ser projetado. }\end{array}$ \\
\hline $\begin{array}{l}\text { 2. Dificuldade de relação com os } \\
\text { materiais }\end{array}$ & $\begin{array}{l}\text { Trabalhar com os materiais não é natural para esse grupo de } \\
\text { participantes. }\end{array}$ \\
\hline 3. Sofisticar ideias & $\begin{array}{l}\text { Os materiais têm capacidade de sofisticação das ideias que já estão } \\
\text { sendo desenvolvidas. }\end{array}$ \\
\hline 4. Compreender a proposta & $\begin{array}{l}\text { A partir dos materiais, é possível que os participantes consigam ser } \\
\text { convencidos do potencial de uma ideia de outro integrante. }\end{array}$ \\
\hline
\end{tabular}

Fonte: elaborado pelos autores

Quadro 2 - Síntese das categorias do grupo focal com designers

\begin{tabular}{ll}
\hline Categoria & Definição \\
\hline $\begin{array}{l}\text { 1. Gerar um ambiente que proporciona } \\
\text { uma condição criativa }\end{array}$ & $\begin{array}{l}\text { A partir dos materiais, surgem novas possibilidades, uma condição } \\
\text { criativa que não seria acessada caso não estivessem sendo utilizados. }\end{array}$ \\
\hline 2. Permitir acessar outros raciocínios & $\begin{array}{l}\text { É um processo de pensar algo de forma mais ampla. Permite que os } \\
\text { participantes acessem outros raciocínios e operações mentais, que não } \\
\text { estão necessariamente relacionadas com a razão. }\end{array}$ \\
\hline $\begin{array}{l}\text { 3. Colaborar com a comunicação para } \\
\text { um convencimento do grupo }\end{array}$ & $\begin{array}{l}\text { O processo com os materiais tem potencial para colaborar com a } \\
\text { comunicação no que diz respeito ao convencimento dos demais } \\
\text { participantes. }\end{array}$ \\
\hline 4. Abrir novas discussões & $\begin{array}{l}\text { A atividade com os materiais tem potencial para trazer para o processo } \\
\text { novas discussões. }\end{array}$ \\
\hline 5. Provocar percursos próprios & $\begin{array}{l}\text { Dependendo do material que está sendo utilizado, leva-se para } \\
\text { caminhos distintos. Os materiais têm seu próprio significado e trazem } \\
\text { esse percurso para o processo. }\end{array}$ \\
\hline 6. Requer abertura dos participantes & \begin{tabular}{l} 
Condição de abertura necessária para que as pessoas que participam \\
\hline
\end{tabular}
\end{tabular}


7. Tornar concreto o que tem em mente Com o protótipo, deixa-se evidente o que se quer dizer. Ajuda a esclarecer e a tornar concreto o que se tem em mente. Os materiais têm potencial de colaborar com a representação e tornar a ideia definida.

Fonte: Elaborada pelos autores

A partir das categorias oriundas dos dois grupos focais possível identificar três tópicos de discussão que estão relacionados ao objetivo de pesquisa. São elas: "Diferenças essenciais entre gestores e designers"; "Dinâmica ágil" e "Potencial da prototipagem para comunicação". Estas são discutidas na sequência.

\section{Discussão}

Foi possível perceber, a partir dos dois grupos focais realizados, que gestores e designers compreendem as potencialidades dos materiais de formas distintas, uma vez que os profissionais operam com suas peculiaridades ao se relacionarem com os materiais. Isto pode estar associado ao seu dia a dia, pois exercem funções e, principalmente, caminhos distintos na execução da sua profissão. Muitas vezes, as atribuições relacionadas à atividade de design estão ligadas a um processo inventivo de trazer à vida novas e melhores opções aos projetos. Os materiais, na visão dos designers, colaboram nessa perspectiva, pois permitem que os participantes acessem uma condição criativa e de abstração das ideias, dando a oportunidade do time de construir modelos de negócios que fogem do tradicional e com potencial de questionar as opções vigentes. Sobre o assunto, uma das entrevistadas comenta:

\footnotetext{
“...eu acho que o desprendimento dos materiais tenha ajudado a explicar a abstração da ideia, porque eu estava falando de uma visão de design estratégico de geração de valor muito mais abstrata e social, mas talvez não lucrativa e na maneira de comunicar isso, tendo esse auxílio tendo esse ambiente de certa forma mais lúdico eu acho que me auxiliou a vender a minha ideia de que a gente não precisaria, tá tudo bem a gente tem que questionar, a gente tem que fazer isso a gente tem que propor um negócio diferente..." (RAQUEL - L168)
}

Tal fragmento corrobora a visão discutida por Michlewski (2008), de que a atividade de design tem a ver com um processo de prototipagem em que procedimentos e etapas evidentes perdem espaço para incertezas, riscos e revisões por meio de uma atividade recursiva que permite ao projetista operar com a liberdade de criação.

Os gestores por sua vez apesar da tentativa em propor um modelo de negócios a partir do uso dos materiais, enfrentaram dificuldades ao longo do processo por não estarem acostumados com atividades dessa natureza. Uma das entrevistadas afirma que:

“É pra nós acho que foi muito difícil, literalmente esse processo de olhar para aquilo, pelo menos pra mim, mas acho que pra ti também foi, porque depois eu comecei a tentar forçadamente a usar alguma coisa daquilo para criar o modelo de negócios, mas aquilo ali não foi como base para pensar o modelo de negócios." (KAREN - L21) 
Cabe destacar que as características comentadas sobre como os designers atuam distinguem-se um pouco das relacionadas à gestão, pois esses lidam muitas vezes com séries históricas e projeções do passado como forma de alinhar o futuro. Isso pode ocorrer pelo fato de que já estão acostumados a lidar com essas situações em vivências passadas. Sobre o assunto, um dos entrevistados designer comentou que o manuseio com materiais foi um processo bastante natural.

Apesar de o contexto empresarial ter se alterado significativamente e as organizações necessitarem de um novo olhar para tudo que vem sendo desenvolvido, atividades de prototipagem dessa natureza ainda são pouco utilizadas para o desenvolvimento de novos negócios. A gestão prioriza olhar para o passado a fim de projetar o futuro. A percepção sobre a construção de um modelo de negócios pela ótica da gestão leva em consideração a maneira como a organização cria entrega e captura valor (TEECE, 2010; CHESBROUGH, 2002; OSTERWALDER, 2012), melhorando a visualização do negócio como um todo, que, muitas vezes, é representado de forma bidimensional por um bussines model canvas, metodologia proposta por Osterwalder (2012). Essa, apesar de buscar aproximar a gestão e o design, não tem a preocupação com o visual e a tridimensionalidade propostas pelo workshop desta pesquisa. Sob essa perspectiva, os gestores entendem que essas propostas podem ser utilizadas em conjunto em momentos distintos, sendo que os materiais têm potencial de colaborar a partir de um momento de sofisticação, refinamento e alinhamento entre todos do que está sendo discutido e produzido. Sobre o assunto, Carlos (L316) comenta que

"Eu enxergo como positivo e só vejo vantagens, mas eu delegaria a responsabilidade disso, pelo menos na experiência de hoje, em um processo fina de representação e sofisticação do modelo."

Ainda, os materiais têm capacidade, segundo os gestores, de ser utilizado para apresentações tanto para os integrantes do time de trabalho quanto para pessoas externas principalmente. Conforme a percepção dos entrevistados, o processo de prototipagem tem grande potencial para um entendimento mais profundo quando utiliza o recurso da tridimensionalidade para uma explanação, principalmente quando são opções e modelos mais complexos. Sobre o assunto, Evaristo (L286) comenta que

\footnotetext{
"um momento que eu pensei bah vou desenhar um canvas aqui que é o que na minha cabeça/mindset é o que é visualizar como é o negócio, mas dai a gente começou a entrar na maquete e eu achei muito mais interessante enxergar nele em um formato de maquete enxergar os pontos e como eles vão se conectar do que no quadrado e no papel. Isso pra mim foi um ponto super positivo"
}

Essa discussão sobre diferenças essenciais entre gestores e designers mostra que, apesar de os profissionais enxergarem potenciais diferentes do que os materiais podem proporcionar para o desenvolvimento de um projeto de construção dos modelos de negócios, tanto gestores quanto designers vislumbram potencialidades positivas e que agregam para a atividade de construção de modelos de negócios. Gudiksen et al. (2014) corrobora essa visão afirmando que o processo de colaboração de diferentes modelos mentais traz benefícios, pois cria configurações e atividades por meio de ferramentas que conduzem a diálogos qualitativos, promovendo a formulação de problemas e cenários futuros do negócio, uma vez que têm potencial de criar novas perspectivas e repensar os modelos de negócios. 


\subsection{Dinâmica Ágil}

Para uma proposta de atividade semelhante a desenvolvida nesta pesquisa, os informantes mencionaram sobre como deve ser o tipo de qualidade da representação. Para eles, parece ser mais interessante que as materializações sejam mais rudimentares, as quais priorizam a discussão e entendimento do time ao em vez de uma preocupação estética. Os entrevistados comentaram que a ideia de construção rápida auxilia na dinamicidade do processo, mas, principalmente, para explicar as ideias e compor o projeto de forma simples e dinâmica. Ainda, em ambos os grupos focais, os informantes mencionaram a qualidade da representação e do detalhamento provenientes dos protótipos. Para essa atividade, os materiais adquiriram uma competência de serem flexíveis e colaboraram com diferentes formas de representação. Os materiais viabilizam uma informalidade, permitem que seja um meio para o processo. Sobre o assunto, um dos participantes comenta que

\footnotetext{
“...ali eu tinha entendido que tinha que ser um pouco tosco mesmo, tosco no sentido de faz rápido e não se preocupa tanto com esse acabamento(...). Nesse tipo de processo eu não sei se teria tanta diferença." (BRENO - L53)
}

Nessa dinâmica móvel, flexível, em quem a importância está na agilidade da construção, importa muito mais o conhecimento adquirido sobre os assuntos discutidos e a união das várias peças e protótipos desenvolvidos ao longo do processo como um todo. O conjunto desenvolvido é o que deve ser levado em consideração, pois o importante em atividades semelhantes é o processo, o aprendizado e as discussões propiciadas e não o objeto desenvolvido em si. Portanto, a estética até pode estar presente, mas não é o conteúdo principal. Os autores Lim et al. (2008), como discutido nos capítulos anteriores, corroboram a visão sobre essa dinâmica móvel dos protótipos, pois, para os autores, quanto mais incompletos, mas que permita o designer explorar, filtrar e examinar as ideias e os caminhos, melhor. Essa incompletude dos protótipos demostra que a importância está na provocação e na competência de abertura e discussão que essa dinâmica promove.

Alguns dos entrevistados reconhecem que, mesmo que fosse importante essa ideia de construção mais rudimentar e rápida, por vezes não é natural para eles. A cobrança por padrões estéticos e protótipos visualmente bonitos acaba pressionando, principalmente os designers para também preocuparem-se com a aparência do projeto. Nesse sentido, uma das informantes menciona que,

\footnotetext{
“...Então se tu não tivesse dito que não era para ter uma preocupação estética eu teria ficado me sentido bem pior ao longo de todo o processo porque eu ia ficar olhando pro colega e pensando, não isso tinha que ficar assim e não assado e eu meio que desprendi disso que pra mim é uma coisa difícil." (RAQUEL - L49)
}

A participante comentou sobre uma preocupação com o visual e que, caso não tivesse sido ponderado no início do workshop que não era necessário se preocupar com a estética dos projetos, mas, sim, no processo como um todo, esse teria um sentimento negativo e de certa forma relacionando-se de outra forma com os gestores que possivelmente teriam uma relação distinta a sua na relação com os materiais. Para Lim et al. (2008), é justamente o potencial de incompletude que permite examinar ideias e qualidades sem a necessidade de criar uma versão final. Essa característica de incompletude cria a oportunidade de o protótipo não prover soluções, 
mas, sim, descobrir novos problemas ou ainda explorar novas soluções.

A discussão sobre esse tópico possibilitou compreender que, para o desenvolvimento de modelos de negócios, a prototipagem assume uma dinâmica flexível em que a relevância está no processo de discussão e provocação que o próprio protótipo direciona. A preocupação estética, quase que intrínseca aos designers, deve ceder espaço para construções rápidas e rudimentares.

\subsection{Potencial da prototipagem para comunicação}

Os entrevistados, gestores e designers, dos dois grupos focais realizados comentaram que os materiais foram eficientes para um processo de apresentação do que as equipes estavam produzindo, sendo uma ótima alternativa para a apresentação do protótipo como um todo, principalmente para os que não estiveram presentes durante a concepção do modelo. Enxergouse um potencial dos materiais para uma apresentação mais plural e rica, em que os elementos servem como protagonistas em um processo de explicação e exemplificação da construção do modelo de negócios idealizado, principalmente quando se trata de uma composição complexa, que leva em consideração diferentes agentes, fluxos e processos, os quais precisam estar todos contemplados no modelo e que, por vezes, a visualização em um formato escrito e em duas dimensões acaba não abrangendo toda a potencialidade que a proposta oferece. A visualização e a apresentação do que foi produzido a partir dos materiais se tornam ainda mais eficazes quando apresentadas para pessoas que não estavam presentes durante todo o processo, na visão dos entrevistados. Assim como comenta um dos gestores no trecho que segue,

“(...) uma grande vantagem é conseguir apresentar um negócio que aparentemente era muito complexo para que outras pessoas que não participaram da nossa discussão conseguissem entender da mesma forma que nós(...)" (LUCAS - L86)

Outro participante também mencionou o quanto os materiais têm potencial para colaborar com a apresentação, principalmente se comparados a outras formas de exposição que o entrevistado tinha conhecimento, assim como demonstra sua fala:

\footnotetext{
"Teve um momento que eu pensei bah vou desenhar um canvas aqui que é o que na minha cabeça/mindset é o que é visualizar como é o negócio, mas dai a gente começou a entrar na maquete e eu achei muito mais interessante enxergar nele em um formato de maquete enxergar os pontos e como eles vão se conectar do que no quadrado e no papel. Isso pra mim foi um ponto super positivo" (EVARISTO - L286)
}

Essa capacidade dos materiais, voltada para apresentação, se aproxima da discussão dos autores Harrison et al. (2015), quando indagam que a construção dos protótipos, nesta atividade o modelo de negócios, é capaz de proporcionar um raciocínio reflexivo, dando suporte ao desenvolvimento e à apresentação das ideias que estão sendo construídas. Ainda tem competência para se envolver em um processo argumentativo e interpretativo das relações e conexões presentes nos materiais e formas, bem como nas propostas como um todo. Dunn (2007) corrobora com a visão quando afirma que as produções materiais representam muito mais que suas dimensões físicas, pois podem contemplar níveis de maior abstração ou simplicidade, mas que se tornam essenciais para promover o pensamento, assim como a comunicação entre designers ou mesmo com o próprio artefato que está sendo produzido.

Esse potencial dos materiais, com o intuito de apresentação para outros indivíduos que não os participantes do processo de construção material, é apenas uma competência de 
apresentação presente nos materiais, uma vez que na atividade foi evidenciada outra potencialidade em termos de exposição do que foi projetado. A apresentação não significa apenas na sua versão final, para um grupo externo, por exemplo. Ainda sobre a apresentação também significa comunicar entre os integrantes do grupo. Ainda, apresentação pode estar relacionada ao que os entrevistados comentaram sobre os materiais também serem úteis para uma exposição, explicação e apresentação do que está sendo discutido com o próprio grupo, significando que esses têm potencial para se comunicar entre os integrantes do grupo, o que colabora com o entendimento homogêneo de todos participantes. Essa visão aparece conforme exprime o informante Lucas (L86)

“(...) até pra gente depois entender os quatro a mesma coisa, porque talvez cada um tivesse uma ideia na cabeça e [...]depois de materializado facilitou muito de todo mundo entender o que a gente estava propondo e para passar para os outros a mensagem."

A compreensão dos autores Lim et al. (2008), de que o protótipo utilizado em projetos e em concepções de design vai além da visão tradicional em que os protótipos são vistos como objetos de testagem, sendo o primeiro da série, mas que ocupam um espaço diferenciado, corrobora com a percepção dos entrevistados. Nessa atividade, foi possível evidenciar uma nova potencialidade para os protótipos construídos. A ideia de poder representar um modelo de negócios a partir de um processo de prototipagem permitiu que os participantes conseguissem apresentar suas ideias de forma diferenciada, trazendo a ideia da tridimensionalidade como forma de visualização do modelo de negócios e tendo o potencial de visualizar todas as conexões, fluxos e agentes que envolvia a proposta. Lim et al. (2008) ainda comentam que esse tipo de atividade, tornar volumétrico, enriquece a percepção dos participantes, trazendo à tona novas assimilações do que está sendo projetado, sendo o protótipo ainda um articulador da equipe para uma visualização de formas mais precisas.

Os materiais condicionam uma percepção de tridimensionalidade que permite uma visualização diferenciada do que está sendo projetado. Esses são capazes de contar histórias e colaborar no desenvolvimento do percurso. Como cada equipe cria um significado para o projeto e para os materiais, fazem com que aquele material seja único, elevando a condição de quem participa ou assiste para um outro patamar de entendimento sobre o processo percorrido, bem como do que se está querendo desenvolver com aquele protótipo. Ainda, esse tópico de discussão demostrou que os materiais estão ligados à comunicação, tanto dos integrantes do grupo, ou seja, colabora com o entendimento uniforme da proposta ou da ideia de um integrante aos demais, mas também está relacionado à comunicação externa do projeto para os que não participaram do processo como um todo.

\section{Considerações Finais}

A realização da pesquisa de campo trouxe considerações importantes sobre os objetivos desta pesquisa, bem como se pode avançar nas discussões sobre a prototipagem na modelagem de negócios na percepção de gestores e designers.

A prototipagem, como meio para desenvolver modelos de negócios, na percepção de gestores e designers objetivo geral deste trabalho, foi vista como vantajosa tanto na visão de gestores quanto designers. Apesar dos profissionais enxergarem distintas vantagens, ambos consideraram a atividade produtiva na construção de modelos de negócios. Para os gestores, essa 
atividade tem maior potencial associada a uma ideia de finalização do que está sendo produzido, tendo potencial de revelar novas ideias e sofisticação do modelo. Já os designers entendem que essa atividade faz parte da natureza de fazer design e colabora em diferentes momentos, sendo uma ótima opção para que pessoas com diferentes competências se entendam a partir do manuseio dos materiais para uma comunicação mais plural e rica. Tem potencial, também, para um processo criativo, para que as ideias possam ser concretizadas a partir do recurso da tridimensionalidade, propiciando discussões que não seriam acessadas caso a representação da ideia fosse a partir de outro recurso visual. Cabe destacar que, na visão dos designers, é preciso que as pessoas estejam abertas para participar de uma atividade dessa natureza, pois requer que essas saiam de sua zona de conforto para projetar ideias de forma diferente. E, quando essas aceitam essa provocação, cria-se um estado de flow para o processo. De qualquer forma, as leituras que fazem esses especialistas nos permitem avançar um passo no sentido de compreender aspectos da potencialidade da prototipagem. Essas visões, contudo, são materiais que devem ser problematizados à luz de outras pesquisas que se ocupem da prototipagem em contextos múltiplos.

\section{Referências}

CHESBROUGH, $\mathrm{H}$. The role of the business model in capturing value from innovation: evidence from Xerox Corporation's technology spin offs companies. Industrial and Corporate Change, v.11, n.3, p.529-555, 2002.

CROSS, Nigel. Design Thinking: Understanding how designers think and work. Editora: Berg, 2011.

DUNN, N. The ecology of the architectural model. Bern: Peter Lang, 2007.

GALEY, Alan. RUECKER, Stan. How a prototype argues. Literature and Linguistic Computing, v.25, n.4, p.405-424, 2010.

GRIENITZ, Volker; SCHMIDT, André-Marcel. Scenario Workshops for Strategic Management with Lego Serius Play. Problems of Management in 21 century, v. 3, p.26-35, 2012.

GUDISKEN, Sune et al. Making Business Models. CoDesign: International Journal of CoCreating in Design and the Arts, v. 10, p. 15-30, 2014.

GURSOY, Benay; OZKAR, Mine. Visualizing making: Shapes, materials, and actions. Design Studies, v. 41, p. $29-50,2015$.

HARRISON, Laura. EARL, Chris. ECKERT, Claudia. Exploratory making: Shape, structure and motion. Design Studies, v. 41, p.51-78, 2015.

INGOLD, T. Making: Anthropology, Archaeology, Art and Architecture. London: Routledge, 2013.

LIM, Youn-Kyung. STOLTERMAN, Erik. TENENBERG, Josh. The Anatomy of Prototypes: Prototypes as Filters, Prototypes as Manifestations of Design Ideas. ACM Transactions on Computer-Human Interaction, v. 15, n. 2, 2008.

MAURI, Francesco. Progettare progettando strategia. Milano: Massin S.p.A.,1996. 
MICHLEWSKI, Kamil. Uncovering Design Attitude: Inside the culture of designers. Organization Studies, v.29, n.3, p.373-392, 2008.

REUTHER, Dieter; JETTON, Sabrina. Stop managing projects and start leading with story. Design Management Review, v.24, n.1, p.28-35, 2013.

TEECE, David J. Business models, business strategy and innovation. Long range planning, $\mathrm{v}$. 43, n. 2, p. 172-194, 2009.

WOOD, Robin. The Future of strategy: the role of the new sciences. In: LISSACK, Michel; GUNZ, Hugh (ed). Managing Complexity in Organizations: a view in many directions. Westport: Quorum books, 1999, p. 118-164. 